\title{
Psicologia de orientação positiva: uma proposta de intervenção no trabalho com grupos em saúde mental
}

\author{
Positive psychology orientation: an intervention proposal \\ for group work in mental health
}

Patrícia M endes Lemos ${ }^{1}$

Francisco Silva Cavalcante Júnior ${ }^{2}$

\footnotetext{
${ }^{1}$ Setor de Psicologia. Centro deAtenção

Psicossocial. Av. José Figueiras $/ \mathrm{n}$, Centro. 62300-000 Viçosa do Ceará CE.

patriciasml@yahoo.com.br.

${ }^{2}$ Departamento de

Psicologia, Universidade de Fortaleza.
}

\begin{abstract}
This investigation aims at presenting a positive approach to psychology applied to the field of mental health in the treatment of patients with mental disorders. The intervention here presented was conducted in therapeutic groups with patients from a psychosocial care center (called CAPS). The analysis of the group work was based on three basic concepts: the humanistic approach and its vision of men and the world, the (con) text method of multiple literacies, and positive psychology. Quantitative and qualitative phenomenological research methodologies were used. The research results were divided into categories based on the group work with patients with depression-related disorders. Seeking for a new model of mental health care aimed at preserving the humanistic approach and the rights of the citizen, the Psychosocial Care Center (CAPS) emerges as a historical result of the construction of the health/disease concept in order to put into practice the principles guiding the psychiatric reform in Brazil. Within this process, a positive approach to psychology is opening horizons for a practice based on a new view of the subject, emphasizing and developing "virtuous" aspects like the possibility of achieving health in its broader meaning, together health promotion and the employment of different psychological practices. Key words M ental health, Positive psychology, Psychopathology, Groups
\end{abstract}

Resumo Esteestudo visa à proposta deuma psicologia de orientação positiva aplicada à Saúde M ental no acompanhamento de portadores de transtornos mentais. Foi realizado em grupos terapêuticos com portadores num Centro de Atenção Psicossocial (CAPS). A análise do trabalho em grupo avaliado baseou-se na abordagem humanista e sua visão de homem e mundo, no método (con)texto de letramentos múltiplos e na psicologia positiva. U saramse as metodologias quantitativa e qualitativa fenomenológica. Os resultados foram listados em categorias que versam sobre a facilitação de grupos de portadores de transtornos depressivos. Ao buscar a prática de um novo modelo em saúde mental, que tenha como aspecto fundamental o zel o pela humanidadee a cidadania dos usuários deste serviço, o CAPS surge como resultado histórico da construção dos conceitos de saúde/doença, com fins de exercer os princípios norteadores da reforma psiquiátrica no Brasil. N este processo de mudança, a psicologia de orientação positiva adentra os horizontes de uma prática fundada num novo olhar sobre o sujeito, buscando a ênfase e o desenvolvimento de aspectos "virtuosos" como possibilidade dealcançar a saúdeem seu sentido mais pleno, caminhando junto à promoção de saúde e instalando um diferencial em relação a práticas anteriores em psicologia.

Palavras-chave Saúdemental, Psicologia positiva, Psicopatologia, Grupos 
Tudo passa - sofrimento, dor, sangue, fome, peste. A espada também passará, mas as estrelas ainda permanecerão quando as sombras de nossa presença e nossos feitos se tiverem desvanecido da Terra. Não há homem que não saiba disso. Por que então não voltamos nossos olhos para as estrelas? Por quê?

Mikhail Bulgakov

\section{Introdução}

Em demasia tem-se discutido sobre um novo conceito de Saúde, que abranja diversos aspectos da vida dos indivíduos para a existência de uma real e ampla condição de bem-estar. O Sistema Ú nico de Saúde (SUS) contempla e garante, em seus princípios fundamentais, os direitos reservados a todos os integrantes de uma sociedade, de forma igualitária, integral e acessível ${ }^{1}$.

A grande questão impeditiva do alcance destes objetivos reside no fato de vivermos em uma sociedade pouco desenvolvida em seu aspecto social, oferecendo escassos recursos em todos os seus eixos - lazer, esporte, educação, cultura, habitação, geração de emprego e renda e, em nosso maior interesse, saúde. Conquistar a saúde em seu sentido amplo éo que se entende por promoção de saúde termo que perpassa todos os setores e equipamentos sociais - lugar a ser descoberto e habitado por todas as disciplinas e competências integradas, agindo em acordo com uma ética interdisciplinar em que se unam condições e capacidades pelo objetivo comum de uma Saúde individual e coletiva.

Pensar sobre o desenvolvimento da Saúde inclui a necessidade de um avanço social complexo. Os esforços político, administrativo e social dãose no sentido de empreender investimentos - ainda de forma segmentada - para que o todo possa então adquirir uma configuração um tanto mais adequada, mais próxima da eqüidade e da integralidade al mejadas.

No segmento da Saúde M ental (SM ), por exemplo, o empenho tem sido na busca por minimizar ou fazer cessar os efeitos negativos e até degradantes das antigas formas de tratar o sujeito adoecido psiquicamente. Para isso, o movimento de Reforma Psiquiátrica tem tomado a frente numa difícil luta contra as esferas de poder opressoras que, já instituídas, reduzem o sujeito à condição de objeto, em intervenções que mais adoecem do que curam eferem intensivamente a cidadania ea condição humana.

Embora hoje a SM seja pensada de maneira ampla, refere-sea esta, neste estudo, no sentido do tratamento e do acompanhamento de usuários (portadores de transtornos mentais) do CAPS, visto que o trabal ho de grupo desenvolvido e analisado aqui fora realizado para estes fins.

Com as mudanças alcançadas pela Luta Antimanicomial no Brasil (no final dos anos oitenta e início dos anos noventa), à qual precederam outros importantes movimentos; a pesquisa e desenvolvimento dos psicofármacos (na década de cinqüenta), especialmente os antipsicóticos que atuam no tratamento das crises psicóticas; a criação da Lei $n^{\circ} 10.216$ - que resguarda os direitos dos portadores de transtornos mentais - a tentativa de fechamento dos hospitais psiquiátricos e o advento da implantação e desenvolvimento dos serviços prestados pelos CAPS; a SM vem redesenhando suas formas de intervenção e tratamento, impondo diálogos entre diferentes eixos teóricos e práxis na operacionalização urgente do novo modelo de saúde pública².

Nesse cenário de perspectivas possíveis, a psicologia tem ocupado papel atuante, engajada no atual movimento de transformação, sendo o psicólogo membro obrigatório das equipes de saúde mental, que exercem práticas complexas, às vezes não tão bem definidas, na atenção psicossocial.

Como a própria psicologia se dilui em diversos contextos e abordagens, produzindo saberes e modos de atuação diferenciados, de acordo com os referenciais seguidos pelos profissionais daárea, entende-se que esta ciência também vive seu momento presentena procura de uma maior solidez eaplicabilidade, na busca por encontrar-se a si mesma?.

De acordo com os pressupostos apresentados, o exercício da psicologia em SM deve estender-se para além da tradicional prática clínica, visto que esta não apresenta subsídios suficientes para os extensivos objetivos desejados. A clínica, como espaço de elaboração subjetiva, emergência de insights e campo de sofrimento e mal-estar, limita-se a tratar especificidades que muitas vezes não contem plam a saúdeem seu sentido amplo eem seus aspectosmais positivos. Ainda que seu exercício se dê através das atitudes favoráveis do terapeuta, as quais podem ser reproduzidas fora do setting terapêutico, e resguarde um olhar social sobre o processo de construção da subjetividade ${ }^{4}$, seus al cances restringemseà mel hora individual, sendo difícil o envolvimento do sujeito com o mundo de maneira mais viva e direta, uma vez que estese relaciona exclusivamente com seu terapeuta e seu campo relacional delimite suas fronteiras em torno dessa mesma relação. Dessa maneira, a vinculação com a coletividadenessa prática dá-seatravés do resgate deexperiências por meio do discurso do cliente ou da fala interventiva do terapeuta, não ultrapassando tais limites. 
Sem negar a profundidade deste processo ou desmerecer sua eficácia em determinadas situações no tratamento do adoecer, cabe-nos pensar a psicologia como campo aberto de facilitação de processos, com vistas ao desenvolvimento do portador de transtornos mentais em seus aspectos interpessoais, cabendo-Ihe o privilégio do regaste destes na comunidade, na sociedade, na cultura a quepertencem ${ }^{4}$.

A partir disso, o trabalho com grupos ${ }^{5-10}$ vem sendo o grande meio pelo qual os psicólogos têm facilitado a inclusão dos sujeitos no mundo, que não se restringe ao subjetivo, embora o constitua e seja por ele constituído. Em uma nova saúde, buscam-se as amplas e heterogêneas relações, muito mais curativas e, fundamentalmente, preventivas das condições do mal-estar psicológico presentes na etiologia das disfunções mentais.

Além de abranger um número maior de usuários, desafogando os consultórios e os horários abarrotados na agenda dos profissionais, o grupo atende a demandas outras, não direcionadas à psicoterapia individual. São exemplos disso: situações pontuais, inter-relacionais, problemas de ordem social-comunitária, patologias leves a moderadas diagnosticadas em usuários sem comprometimento severo da personalidade.

Os alcances do grupo também atendem à demanda institucional da estabilização ou melhora do quadro apresentado pelo portador do transtorno ese aproxima dos pressupostos do conceito de saúde como bem-estar biopsicossocial.

A análise do trabalho em grupo desenvolvido alicerçou-se em três vertentes principais: a abordagem humanista8-12 e sua visão de homem e de mundo, o método (con)texto de letramentos múltiplos $^{13-16}$ e a psicologia positiva ${ }^{17}$.

A corrente humanista da psicologia, também conhecida como terceira força $a^{3,18}$, ressalta aspectos positivos do desenvolvimento humano, destacando em sua fundamentação conceitos como liberdade, conscientização e experiência enquanto elementos essenciais da condição existencial do homem. A fenomenologia e o existencialismo ${ }^{11,19-21}$ fundadores da terceira força, são linhas afins que se complementam na tentativa de enfatizar a capacidade de análise do fenômeno subjetivo na consciência, por meio da percepção experienciada, sob o solo da vida mesma, da existência concreta. 0 humanismo em psicologia reporta o homem a si próprio, à sua natureza imbricada numa real idade mundana, em que homem e mundo se constituem mutuamente e se relacionam como duas mãos entrelaçadas (não se sabe qual mão está tocando a outra). Essa concepção merleau-pontyana ${ }^{19,22}$ de- fine bem a construção de uma subjetividade- adoecida ou não - realizada unicamente nessa relação mundana, não podendo dela ser dissociada.

0 mundo fenomenológico não é o ser puro, mas sim o significado que transparece na interseção de minhas experiências edas experiências do outro, pela engrenagem de umas com as outras, ele é, portanto, inseparável da subjetividade e da intersubjetividade que fazem sua unidade pela retomada de minhas experiências passadas nas minhas experiências presentes, das experiências do outro na minha vida22.

0 pensamento rogeriano humanista ${ }^{9}$ aponta em direção à crença na orientação positiva do homem a partir do conceito de tendência atualizadora. 0 referencial da abordagem centrada na pessoa traz sua grande contribuição ao priorizar as condições facilitadoras que fazem emergir eimpulsionam a operacionalização dessa ten dência. Deacordo com Rogers, todo indivíduo édotado de potencialidades voltadas para o desenvolvimento pessoal no empenho pela criação de uma "vida boa".

Por meio de um clima de aceitação, autenticidade empatia, o indivíduo passa a implicar-se no processo de tornar-se pessoa, de ser o que é, para que a vida siga seu curso natural. E o curso mesmo da vida é direcionado para a auto-realização, para a experiência de satisfação e voltado para a plenitude no campo inter-relacional ${ }^{8}$. Como uma correntefavorável de esperança, o movimento da vida discorreesemultiplica, perpassando suas experiências legítimas, superando a dor e privilegiando espaços de bem-estar na construção de uma coletividade que também venha a se auto-atualizar. A orientação positiva proposta por Rogers faz-se presente em abordagens individuais e de grupos.

0 grupo constitui lugar privilegiado da troca de experiências. Os partici pantes auxiliam-se mutuamente na compreensão do sofrimento e em sua superação. 0 processo grupal permite 0 envolvimento dos participantes por meio de um elo que se estabelece nas interações, no espaço intersubjetivo ${ }^{5}$. A condição de implicação mútua na esfera do entre é o que possibilita a transformação pessoal e mobiliza a mudança social. Ao criar laços de solidariedade entre os participantes, o grupo constitui uma comunidadeque se relaciona a partir das lentes da cultura pelas quais as pessoas enxergam 0 mundo ${ }^{15}$.

0 portador de transtorno mental deve ser 0 centro do tratamento, não se enfatizando a doença, mas a existência do doente, que é sujeito em potencial. Ainda que as defesas rígidas, as estruturas resistentes à mudança e os modos de funcionamento comprometidos impeçam ou emperrem a atual ização de uma ten dência à real ização esatis- 
fação, o portador está em processo de tornar-se, e sua melhora é sempre uma possibilidade ${ }^{9,22}$.

A incongruência básica ${ }^{9,10}$ apresenta-se na realidade do portador. Sua psicopatologia define-se em termos de incoerência entre o pensar e o dizer, entre o querer e o fazer, entre o ser e o expressar-se. Faz-senecessário o resgate da consciência de si, para o portador criar novos sentidos para sua condição existencial e tomar posse de suas potencialidades para ser o que deseja, plenamente. Tanto em disfunções neuróticas como em psicoses, a incongruência interfere no livrefuncionamento organísmico, impedindo a condição de saúde.

Saúde psicológica significa flexibilidade, opondo-se à rigidez ${ }^{21}$. Ao fixar-se numa postura patológica repetitiva e paralisada, o portador se vê impedido de exercer as múltiplas possibilidades de uma vida boa. Em alguns transtornos, ele nem sequer pode reconhecêlas, por se perceber inteiramente absorto em seu sofrimento e nos demais desdobramentos desagradáveis que ele determina à sua vida.

A tendência atualizante encontra-se com seu funcionamento comprometido na patologi $a^{9,10}$. Seja por uma prevalência de fatores biológicos, emocionais ou socioeconômicos, a patologia se desenvolve ao impedir o livrefluir dessa tendência. $\mathrm{N}$ ão éprioridade saber onde a doença começa ou 0 porquê, mas sim como ela se processa, com que função passou a se configurar e quais os meios de minimizar ou cessar a dor vivida. Ainda que a doença possa ser entendida como uma estratégia de fensiva do organismo, sinalizando a necessidade de mudança, ela se caracteriza mais apropriadamente como um apelo dessa tendência querendo se atualizar. Na concepção rogeriana positivamenteorientada, a aceitação incondicional garante o apreço das experiências do outro (portador do transtorno), independente dequaisquer condições, para que haja a compreensão mais realista de sua experiência - denominada compreensão empática - porém, isso não significa dizer que ao adoecer 0 organismo esteja funcionando plenamente, apenas o adoecimento constitui a forma como o desejo dese realizar encontrou para comunicar-se.

Não negando os pólos negativos da existência, tais como: a resistência, os mecanismos neuróticos de defesa, a divisão psicótica, a incongruência e o mal-estar, a inflexibilidade dos distúrbios de personalidade, a concepção rogeriana simplesmente busca dar ênfase às condições positivas, facilitadoras de uma relação que delineia uma configuração nova, mais plena, mais satisfatória, mais saudável.

Em meio a críticas, às vezes infundadas, acerca do trabalho dos profissionais de SM , esta investigação também deseja o esclarecimento do que seja a psicopatologia e das formas deseu tratamento, apresentando as conseqüências favoráveis de um arsenal teórico-prático orientado para a positividade.

Vandenberg, Gendlin, De Nicola, citados por M oreira ${ }^{22}$, perfazem uma psicopatologia humanista, inserindo o modelo fenomenológico na descrição dos transtornos mentais. Analisam severos transtornos, como a psicose, contribuindo para sua compreensão no sentido descritivo e existencial. N essa perspectiva, a condição de saúde define-se como abertura à experiência, como a realização da tendência atualizante, enquanto a doença quer dizer um "afastamento da responsabilidade de existir", na qual o indivíduo se encontra aprisionado num mundo particular eseparado do mundo compartilhado.

Em SM, os manuais de psiquiatria ${ }^{23,24}$ atuam como requisitos norteadores para o diagnóstico e o prognóstico de transtornos mentais, não constituindo a última palavra sobre a realidade do portador. $\mathrm{Na}$ tentativa de universalizar a linguagem e 0 entendimento das patologias, estes guias são ferramentas de consulta e de orientação, frutos de pesquisas que ressaltam a importância de se considerar a cultura, que (re) desenha os moldes de suas patologias e dita o que seja saudável e o que seja adoecer num contexto específico. Confundem-se as classificações dos transtornos mentais com sua descrição fenomênica. Cabeo esclarecimento, portanto, de que as primeiras dizem respeito à nosografia dos transtornos, enquanto que à descrição destes, tal qual se apresentam, sem terminações classificatórias ou taxativas, dá-se o nome de psicopatologia. Cabe a cada profissional e às equipes de SM lançar aos portadores o olhar sensível voltado para a sua existência e seus potenciais de mel hora.

Realizar o acompanhamento de portadores de transtornos mentais sem o conhecimento prévio de psicopatologia em seu sentido amplo, da nosografia dos transtornos, do processo social de criação dos conceitos de saúde e doença ${ }^{25}$ e as nuanças culturais de cada comunidade seria proceder de forma profundamentenegligente. É preciso conhecer paratransformar. Neste modo de pensar, todos os aspectos assumem sua relevância, ainda queo lugar privilegiado seja o reconhecimento das potencialidades do portador, de sua família, de sua comunidade, no lidar com a patologia e em sua transcendência.

Levando em consideração todos os aspectos importantes no conhecimento do adoecer psíqui$\mathrm{co}$, pode-se partir para as estratégias de intervenção utilizadas. Entre estas, a aplicação do método (con)texto de letramentos múltiplos ${ }^{13-16}$ na facilitação dos grupos terapêuticos fora de grande viabilidade na evolução favorável dos portadores. A es- 
colha desta forma de intervenção deu-se pel os pressupostos do método adequarem-se aos objetivos do trabalho com grupos de conotação positiva.

Ao estabelecer como regra na condução das atividades a atitude fundamental do "sem julgamentos", os participantes sentem-se abertos a experiências desprovidas de conteúdos negativos, advindos de comentários ou expressões depreciativas, que reduzam a si mesmos ou aos outros. Com isso, há a criação de um clima propício de respeito às diferenças e abertura às experiências de troca e de exposi ção de conteúdos emocionais.

Sendo uma metodologia para o trabalho em grupo, desenvolvida tanto na psicologia como na educação, embasa seus fundamentos na terapia cultural - prática através da qual os participantes realizam a leitura demundo a partir de seu contexto cultural; no conceito de letramentos - enquanto "conceituação e práticas sociais de leitura, deescrita e da linguagem" que são expressas por meio de múltiplas formas de representação de sentidos; e na aprendizagem experiencial - aquelaquepermite a interação entre a educação e a vida, experiência organísmica deencontro com o imediato, incluindo os aspectos cognitivo e não-cognitivo ${ }^{16}$.

No método (con)texto de letramentos múltiplos, os participantes são convidados a expressar seus pensamentos, sentimentos e lembranças de maneira livre ecriativa, recorrendo às suas próprias ferramentas derepresentação do mundo. Na aprendizagem compartilhada, tornam-se autores de suas vidas e são valorizados em seus potenciais. Em sua aplicação psicológica, o método facilita o encontro dos participantes com suas próprias experiências, ao vivenciarem a liberdade de representar seus sentidos partindo de sua experiência pessoal. Valoriza, assim, o conhecimento cultural e vivencial de cada integrante, sendo a troca de experiências estimulada na criação de um clima livre de julgamentos e preconceitos. Ao enfatizar as potencialidades humanas e seu poder transformador, a metodologia em questão soma mais um elemento no tripé de uma intervenção de orientação positiva em psicologia.

Por último, ressaltamos a psicologia positiva ${ }^{17}$ propriamente dita, que tem alcançado espaço nos últimos anos nas ciências sociais e psicológicas, ao considerar os aspectos ditos positivos como a felicidade e outras emoções semel hantes, além de seus benefícios e maneiras de desenvolvêlos. Esta nova ciência tem buscado o rigor de pesquisas que evidenciem e identifiquem intervenções promotoras do bem-estar e da qualidade de vida das pessoas. Por este motivo, suas práticas têm sido pensadas na esfera da SM em seu amplo entendimento.

A pós a ênfase demasiada no mal-estar e na patologia, na tentativa de apreender os fenômenos disfuncionais da mente, a psicologia volta seu ol har para a saúde e todos os aspectos positivos da condição humana, acreditando que o enfoque dado ao tratamento tem a ver diretamente com aquilo a que se direciona este olhar das disciplinas e dos profissionais.

Yunes ${ }^{17}$ destaca a missão da ciência psicológica na construção de uma visão do ser humano com ênfase nos aspectos virtuosos. A psicologia positiva tenta levar os psicólogos a adotarem uma postura mais apreciativa dos potenciais, das motivações e das capacidades dos indivíduos, buscando transformar as antigas questões em novas oportunidades de compreender eventos psicológicos como otimismo, altruísmo, esperança, alegria, satisfação, e outros tão importantes para a investigação quanto depressão, ansiedade, angústia e agressividade. Chama atenção para o estudo do conceito de resiliência enquanto capacidade profunda para a superação de crises em situações adversas, estando presente em indivíduos, comunidades e instituições.

Por não se delimitar exclusivamenteà corrente da psicologia positiva, optou-se por usar o termo psi cologia deorientação positiva nesta pesquisa, uma vez que outras correntes de pensamento se mesclam na interação de conceitos para a compreensão otimista da realidade existencial do portador e suas possibilidades de tratamento.

A compreensão de "positivo" expressa aqui se assemelha àquela definida por Bradburn, citado por Giacomoni ${ }^{26}$, em que o bem- estar constitui um estado que denota uma prevalência do afeto positivo sobre o negativo. N essa perspectiva, a felicidade é pensada como o equilíbrio en tre os dois aspectos, levando em conta o tempo que um indivíduo passa experimentando emoções positivas em sua vida ou o quanto se encontra predisposto a estas.

Caracterizando a realidade institucional pesquisada, destaca-se que os processos grupais de senvolveram-senum Centro de Atenção Psicossocial (CAPS), tipo II ${ }^{27}$ - o qual atende a uma população de 70.000 a 200.000 habitantes, em sua maioria pertencentes a comunidades de baixa renda. o CAPS constitui um serviço de saúde aberto e comunitário do SUS, lugar de referência no tratamento para pessoas acometidas por sofrimento psíquico, desde psicoses, neuroses graves a demais quadros, cuja severidade e/ou persistência justifiquem sua permanência num dispositivo de cuidado intensivo, comunitário, personalizado e promotor de vida. Formado por uma equipe multidisciplinar, o CAPS em análisesitua-senum município da região norte do estado do Ceará. 
0 perfil diagnóstico dos usuários deste serviço, referente ao período de novembro de 2004 a setembro de 2005, apresentou-se de acordo com o Gráfico $1^{23}$.

A partir do perfil apresentado, constatou-seum número maior de transtornos fóbico-ansiosos e depressivos. No atendimento a esta clientela - representante da maior parte dos usuários do serviço -, atuava o setor de psicologia em seus atendimentos individuais e em grupo, além de outras atividades.

Os grupos terapêuticos específicos por patologia foram o campo de nossa coleta de dados. Facilitados por um psicólogo e, por vezes, contando com a co-facilitação de outro técnico da equipe, os grupos destinavam-se aos portadores acima relacionados. Em particular, nos deteremos aos grupos formados por portadores de transtornos depressivos. De caráter breve, esses instrumentos visavam a fornecer apoio psicológico eeducar acerca do tratamento da depressão $0^{28,29}$, facilitando a emergência de conteúdos emocionais na criação de espaço apropriado de livre expressão, escuta e troca deexperiências, bem como deaprendizagem decondutas que contribuíssem para o resgate de condições psíquicas facilitadoras de um prognóstico favorável, minimização do número de internamentos e para a (re)inserção social. Os critérios de inclusão nos grupos eram: usuários do CAPS, maio- res de 18 anos, com diagnóstico para a transtornos depressivos (F32, F33, F34.1 - CID), não estáveis, em caráter intensivo (usuários querecebiam 22 atendimentos/mês) ou semi-intensivo (usuários com doze procedimentos/mês). Os processos grupais ocorriam em doze encontros semanais, com o máximo de doze usuários. A metodologia na condução dosgrupos esteve fundamentada principalmenteno método (con)texto deletramentosmúltiplos ${ }^{16}$, utilizando em menor escala recursos da terapia comunitária ${ }^{30}$ e da dinâmica de grupo ${ }^{31}$.

$\mathrm{Na}$ busca de compreender quais os aspectos emergentes da prática de grupos orientada positivamente e sua importância no tratamento dos transtornos mentais, utilizaram-se as metodologias quantitativa e qualitativa fenomenológica de pesquisa. Considerou-se que o método fenomenológico na investigação da vivência dos usuários permite uma maior aproximação de suas experiências autênticas e imediatas, através do envolvimento existencial dos pesquisadores e seu posterior distanciamento reflexivo ${ }^{19,21}$.

Foram analisados os processos interpessoais em três grupos de portadores de transtornos depressivos, por meio de observações, entrevistas semi-estruturadas realizadas durante os encontros, intervenções do terapeuta, expressões dos participantes e impressões dos profissionais da equipe acerca do trabalho com os grupos terapêuticos.

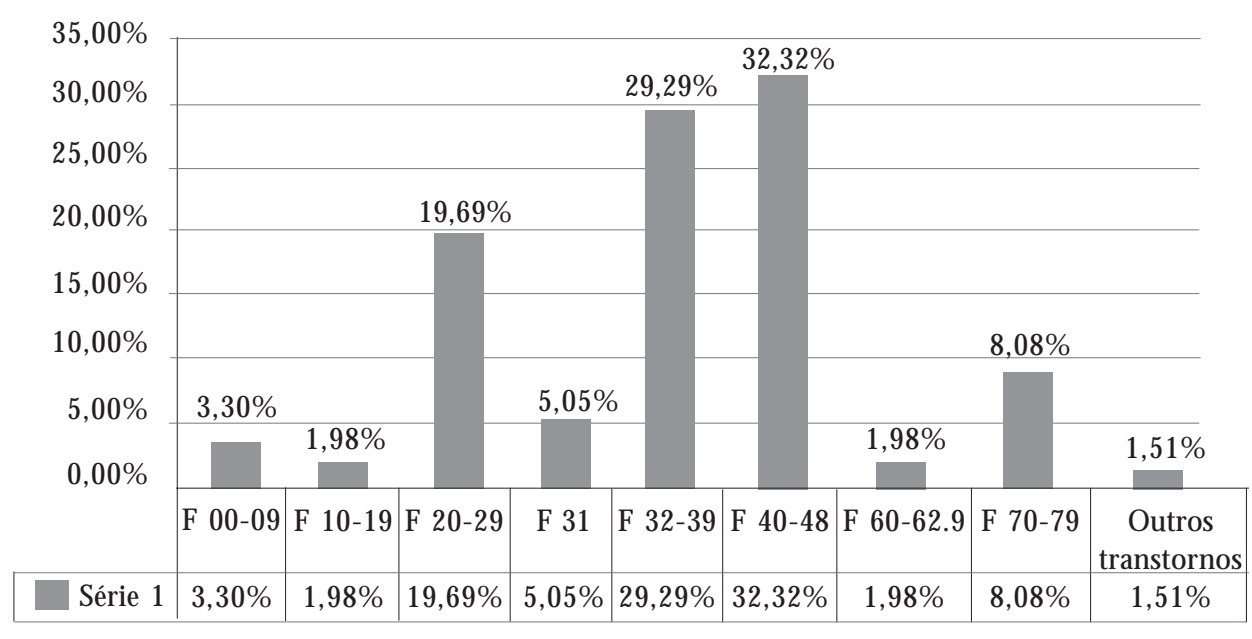

Gráfico 1. Perfil diagnóstico dos usuários do CAPS II. 


\section{Resultadosediscussão}

Para considerar positiva uma categoria, levaramse em conta os seguintes aspectos: 1) a evolução dos usuários em relação à patologia: o percentual de usuários que tiveram evolução favorável foi de $62,59 \%$ no total dos grupos avaliados, considerando-se "evolução favorável" para aqueles que alcançaram maior estabilidade do quadro psíquico ou ausência de sintomas depressivos, o que fora avaliado pela passagem de usuário intensivo para semi-intensivo, de semi-intensivo para não-intensivo (referente a usuários que recebiam três atendimentos/mês) ou ambulatório, o recebimento da alta do serviço ou ainda aqueles que receberam alta do tratamento psicológico e permaneceram em atividades ocupacionais; 2) o reconhecimento da sensação de melhora relatada pelos usuários participantes após a conclusão o grupo; 3) a avaliação psiquiátrica realizada em consultas posteriores ao término do grupo para verificar a mudança ou permanência do plano terapêutico; 4) o acompanhamento da evolução dos usuários atendidos em psicoterapia individual; 5) a confirmação da equipe sobre a evolução positiva dos usuários.

0 processo grupal orientado positivamente trouxe a emergência de categorias positivas, que foram trabal hadas no decorrer do tempo de realização do grupo e contribuíram para uma condição existencial mais saudável na experiência dos usuários. As categorias negativas dizem respeito às limitações encontradas neste processo. Todas as categorias foram apreendidas a partir do que se denominou etapas do processo grupal - inicial (caracterizada pela resistência, pelo pessimismo e pela rigidez dos usuários); intermediária (caracterizada pela evolução favorável de parte dos usuários e inflexibilidade de outros, e relativa dificuldade de adesão a aspetos positivos da existência); final (aquela em que os usuários elaboravam o processo de saída do grupo e realizavam sua auto-avaliação, em que se observou a assimilação dos aspectos positivos). Dentre as formas de expressão utilizadas pelos usuários para comunicar os aspectos positivos e negativos, foram produzidos e compartilhados: conteúdos verbais, colagens em grupo, desenhos e poesias. Os nomes dos usuários apresentados são fictícios, visando à preservação do anonimato.

\section{Categorias negativas}

Traços rígidos de personalidade

Entre outros fatores, um dos grandes impedimentos na evolução favorável de transtornos depressivos está na rigidez da personalidade ${ }^{28,29} \mathrm{do}$ portador. Os fatores da personalidade estão ligados ao grau de maior dificuldade ou facilidade de o paciente modificar seu modo de pensar e seus padrões de comportamento. Por isso, alguns não evoluem satisfatoriamenteem atividades com grupos de caráter breve.

Prevalência do fator biológico

Quando há a prevalência de fatores biológicos na origem da patologia, o tratamento medicamentoso torna-se mais eficaz. Ainda que o trabalho psicológico auxilie na capacidade imunológica do organismo ${ }^{32}$, as recidivas são imprevisíveis, principalmente nas depressões crônicas.

\section{Dificuldades contextuais de adesão}

a conceitos positivos

Tanto na equipe multidisciplinar, como nos outros setores relacionados à Saúde M ental, existiu certa resistência em se pensar e enfatizar aspectos positivos ou a prevalência do hábito de valorizar o mal-estar, a patologia e as limitações no tratamento do portador de transtornos mentais, 0 que dificultou a propagação e disseminação de condutas mais positivas.

\section{Limitações no processo de criação}

de redes sociais

0 desafio da promoção de saúde está em realizar uma boa articulação entre setores e criar espaços promotores de saúde nas próprias comunidades, para que o portador possa estar inserido socialmente ese manter em contato com instrumentos deapoio ebem-estar, não necessitando adoecer. Era comum a resistência de portadores em receber alta do serviço por não quererem desfazer o vínculo com aquele que, muitas vezes, era o único espaço onde se sentiam apoiados e em contato positivo com as pessoas, experienciando coisas boas.

\section{Categorias positivas}

\section{Desenvolvimento pessoal}

Refere-se ao grau de amadurecimento - descrito por Rogers ${ }^{9,10}$ como uma das metas da facilitação de processos - relatado pelos usuários, aos valores aprendidos eà exaltação da experiência de compartilhar seu sofrimento com outras pessoas que vivenciavam situações semelhantes. Esta cate- 
goria também inclui a auto-avaliação desi no processo, realizada por todos, como na verbalização de Lúcia: "eu consegui cuidar dos meus problemas sem descontar nos outros, como fazia com minha filha" - referiu durantea exibição deum filme, com os olhos marejados, enquanto beijava a filha de oito anos, anteriormente alvo de sua agressividade e depositária de suas frustrações.

\section{Solidariedade}

Diz respeito ao aprendizado de direcionar o olhar para o outro, mesmo na experiência de dor o que al ivia o sofrimento. “M esmo a gente estando doente, tem gente que sofre mais, equando a gente ajuda, se sente melhor", afirmou Maria.

\section{Comemoração}

Tem a ver com a necessidade de celebração, de ênfase ao aspecto positivo. Ao término do grupo, sem nenhuma orientação prévia do terapeuta, os usuários sempre se reuniam para uma cel ebração. M esmo sem condições econômicas favoráveis, todos se cotizavam para a realização de uma "festa" em que desfrutavam da alegria pela melhora que conquistaram. Neste momento, era visível a transformação da tristeza inicial na alegria da etapa final.

Aceitação do negativo na existência

Faz parte do quadro depressivo a postura rígida do portador na sua severa dificuldade em aceitar perdas/frustrações e superá-las ${ }^{28,33}$. Ao apegarem-se a dor do passado, os portadores sentemse culpados ou vitimados e não conseguem perdoar a si mesmos ou à vida pelo quelhes ocorreu. Ao vivenciarem essa dor e expressarem-na, discutindo acerca da presença do sofrimento na vida de todos os participantes, e reconhecendo que, em última instância, a dor psíquica traz um aprendizado deveras enriquecedor, os usuários conseguem adquirir certa resignação ou até mesmo a libertação da dor. "Eu já até perdoei o homem que matou meu marido, procuro não pensar mais nisso, Deus é quem sabe, se eu tinha de passar por isso", relatou Flor, que já vinha lutando pela superação dessa perda há dois anos.

\section{Serenidade}

Chamou-se serenidade a esta sensação alcançada, também expressada pelos usuários como paz interior, calma, relaxamento. Mostrou-se em expressões espontâneas de se abraçarem uns aos outros a cada encontro, ou de realizarem algum tipo de oração que os reportasse à tranqüilidade desejada. Ana conduziu espontaneamente o grupo na oração da serenidade: "Senhor, dá-nos a sereni- dade para aceitar aquilo que não podemos mudar, a coragem para mudar as coisas que podemos e a sabedoria para diferenciar umas das outras".

\section{Felicidade}

Grande parte dos usuários expressou claramente seu desejo de ser feliz. Era por isso que estavam ali. Ser feliz tinha a ver com estar saudável. Em todos os grupos, houve expressões de querer encontrar felicidade quando os usuários refletiam sobre os motivos para estarem presentes nos encontros, participando do processo. Enquanto nos dois primeiros grupos, o terapeuta optou por chamar o grupo de Phoenix, realizando a analogia entre a possibilidade de "renascer das cinzas" tal como a ave mitológica e de sair do sofrimento intenso vivenciado na depressão; no terceiro grupo, ao deixar que os próprios usuários escolhessem o nome do grupo a que pertenceriam, este passou a ser denominado: "Buscando a felicidade".

\section{Consideraçõesfinais}

A experiência de exercer uma psicologia orientada positivamenteéreveladora das potencialidades dos seres humanos, mesmo com certo grau de impedimento e comprometimento impostos pela patologia. 0 portador constitui um ser de potencialidades e deve ser reconhecido como tal. Não há meios de pensar a (re) inserção social ea promoção de saúde sem uma visão otimista dos processos humanos que esteja impregnada na política, nas disciplinas, na gestão social, enfim, em todos os setores.

Da dimensão da dor é possível extrair seu pólo oposto - o bem-estar. No entanto, não se poderia propor a exclusão dos ditos aspectos negativos de quaisquer práticas psicológicas sem correr o risco de cair na ideologia da auto-ajuda ou do mero aconsel hamento, negando a rigidez de uma dor psíquica presente na experiência imediata do portador. Tal atitude significaria ao mesmo tempo negligência ealienação.

A existência humana contempla infinitos pares de opostos que se completam, se intercalam e se sobrepõem em movimentos diferentes, de modo que não haveria meios de viver sem sofrer ou de apenas sofrer sem poder viver plenamente.

A grande questão se fundamenta na prevalência de fatores bons, virtuosos, realizadores, não por intermédio de uma moralidade ultrapassada ou para a reparação de carências e danos numa prática caridosa ou penosa da psicologia, mas pelo reconhecimento de um desejo da existência direcionado ao bem comum e à felicidade. Libertos das 
determinações do mal-estar tão familiarizado, vislumbrando possibilidades de experienciarem uma vida voltada para os aspectos positivos, os portadores de transtornos mentais puderam se reconhecer em condições novas, mais plenas e, porque não dizer, mais felizes.

\section{Colaboradores}

PM Lemos participou da concepção e redação do artigo, análise de dados e como psicóloga-facilitadora dos grupos investigados; FS Cavalcante Júnior contribuiu para a fundamentação teórica e realização da pesquisa.

\section{Referências}

1. Brasil. Constituição: República Federativa do Brasil. Título VIII. Cap. II. Seção II: Da Saúde. Brasília: Senado Federal/Centro Gráfico; 1988.

2. GTSM (Grupo de Trabalho em Saúde Mental). Apostila de Multiplicador em PSF Saúde M ental. Rio de Janeiro: Escola Politécnica de Saúde Joaquim Venâncio da Fundação Oswaldo Cruz; 2002.

3. Figueiredo LCM. Matrizes do pensamento psicológico. Petrópolis: Vozes; 1991.

4. Bock AM B, Gonçalves M GM, Furtado O, organizadores. Psicologia sócio-histórica: uma perspectiva crítica em psicologia. 2a ed. São Paulo: Cortez; 2002.

5. Lane STM, Raffaelli R, Naffah A, Rahal LA, Sivieri LH, Almeida SA, Fregni G, Zugueib J, Luz W. Uma análise dialética do processo grupal. Cadernos de Psicologia PUC 1981; 11:79-98.

6. Tellegen TA. Gestalt e grupos: uma perspectiva sistêmica. São Paulo: Summus; 1994.

7. Rogers CR, Wood JK, O'H ara M M, Fonseca AHL. Em busca de vida: da terapia centrada no cliente à abordagem centrada na pessoa. 2ạ ed. São Paulo: Summus; 1983.

8. Rogers CR. Um jeito de ser. São Paulo: EPPU; 1993.

9. Rogers CR. Tornar-se pessoa. 5a ed. São Paulo: Martins Fontes; 1997.

10. Rogers CR. Psicoterapia e relações humanas. Belo Horizonte: Interlivros; 1997.

11. Moreira V. Para além da pessoa: uma revisão crítica da psicoterapia de Carl Rogers [tese]. São Paulo (SP): PUC; 1990.

12. Angerami-CamonVA. Psicoterapia existencial. São PauIo: Thompson Pioneira; 2002.

13. Cavalcante Jr FS. 0 método (con) texto na escola do sujeito: a experiência de ler, escrever e avaliar de alunos no ensino superior. Fortaleza: Unifor; 1998.

14. Cavalcante Jr FS. Sujeito, palavra e cultura: um estudo etnográfico da comunicação escrita de alunos no ensino superior [projeto de pesquisa]. Fortaleza: Unifor; 1999.

15. Cavalcante Jr FS. Círculos de letramentos: uma prática de terapia cultural. Revista de Psicologia UFC 1999; 17/18:14-22.

16. Cavalcante Jr FS. Por uma escola do sujeito: 0 método (con)texto de letramentos múltiplos. Fortaleza: Edições Demócrito Rocha; 2001.

17. Yunes MAM. Positive psychology and resilience: focus on the individual and families. Psicol. estud. [periódico na Internet]. 2003 [acessado 2006 abr 29]; 8(n. esp):[cerca de 10 p.]. Disponível em: http://www. scielo.br/scielo.php?script=sci_arttext $\&$ pid $=S 1413$ 73722003000300010

18. M aslow AH. Introdução à psicologia do ser. 2ª ed. Rio de Janeiro: Eldorado; 1973. 
19. Moreira V. O método fenomenológico de MerleauPonty como ferramenta crítica na pesquisa em psicopatologia. Psicol. Reflex. Crit. [periódico na Internet]. 2004 [acessado 2006 mai 8]; 17(3):[cerca de 10 p.]. Disponível em: http://www.scielo.br/scielo.php?script $=$ sci_arttext\&pid $=$ S0102-79722004000300016\&Ing=pt $\& n r m=i s o$

20. Dartigues A. O que é fenomenologia? São Paulo: M oraes; 1992.

21. Forghieri YC. Psicologia fenomenológica: fundamentos, métodos e pesquisa. São Paulo: Pioneira; 1993.

22. Moreira V. O enfoque centrado na pessoa no tratamento de um caso de esquizofrenia. Psicologia: Teoria e Pesquisa 1987; 3:262-281.

23. Organização Mundial de Saúde. Classificação de Transtornos M entais e de Comportamento da CID-10: Descrições Clínicas e Diretrizes Diagnósticas. Porto Alegre: ArtM ed; 1993.

24. American Psychiatric Association. M anual diagnóstico e estatístico de transtornos mentais. (DSM -IV-TR). 4a ed. Porto Alegre: Artmed; 2002.

25. Foucault M. História da loucura. São Paulo: Perspectiva; 1993.

26. Giacomoni C. Bem-estar subjetivo: em busca da qualidade de vida. Rev. Temas de Psicologia 2004; 12(1):43-51.

27. Brasil. M inistério da Saúde. Secretaria de Atenção à Saúde. Departamento de Ações Programáticas Estratégicas. Saúde M ental no SUS: os Centros de Atenção Psicossocial. Brasília: Ministério da Saúde; 2004.

28. Solomon A. O demônio do meio-dia: uma anatomia da depressão. Rio de Janeiro: O bjetiva; 2002.

29. Del Nero HS. 0 sítio da mente: pensamento, emoção $e$ vontade no cérebro humano. São Paulo: Collegium Cognitio; 1997.

30. Barreto A, Boyer J-P. 0 índio que vive em mim: 0 itinerário de um psiquiatra brasileiro. São Paulo: Terceira M argem; 2003.

31. Lima LO. Dinâmica de grupo. Petrópolis: Vozes; 1969.

32. Alexander F. M edicina psicossomática: seus princípios e aplicações. Porto Alegre: Artes M édicas; 1989.

33. Abreu CN, Salzano FT, Vasques F, Cordás TA, organizadores. Síndromes psiquiátricas: diagnóstico e entrevista para profissionais de saúde mental. Porto Alegre: Artmed; 2006.

Artigo apresentado em 02/06/2006

Aprovado em 06/07/2007 